\title{
Exploring Millennial's perceptions towards luxury fashion wearable technology
}

\author{
Marta Blazquez \\ Department of Materials, The University of Manchester, Manchester, UK, and \\ Bethan Alexander and Karie Fung \\ London College of Fashion, University of the Arts, London, UK
}

\begin{abstract}
Purpose - This study aims to examine the relationship between key value propositions of luxury fashion smartwatches, consumer attitudes and their purchase intentions, and to explore Millennial consumers' overall perceptions of using these wearable technologies.

Design/methodology/approach - The research adopts a mixed methods approach. Quantitative enquiry consisting of 312 respondents was followed by two qualitative focus groups in order to provide a more comprehensive understanding of the issue.

Findings - The findings indicate that functional, individual and social factors influence Millennial consumers' adoption intention of luxury fashion smartwatches. Empirical results reveal that perceived hedonism and usefulness are the most important factors that motivate adoption intentions, followed by subjective norm and perceived conspicuousness, indicating that luxury smartwatches are perceived as both a technological device and luxury fashion accessory.

Originality/value - Given extant research on luxury fashion smartwatches is limited, this study contributes to this unique research stream by exploring Millennial's perceptions towards using these new generation smartwatches. This research develops a theoretical framework building on technology adoption model 2 (Venkatesh and Davis, 2000), theory of reasoned action (Ajzen and Fishbein, 1975) and luxury perception models (Wiedmann et al., 2007).
\end{abstract}

Keywords Consumer attitudes, Millennials, Technology acceptance model, Wearable technology,

Luxury fashion smartwatches

Paper type Research paper

\section{Introduction}

Wearable technologies have become more readily available and widespread in the market and are expected to grow from 526 million in 2016 to over 1.1 billion in 2022 (Statista, 2019). Among wearable technologies, smartwatches have increased their popularity and become part of daily life (Dehghani and Kim, 2019). However, in spite of the increasing interest from industry, research on wearable technologies has been mostly focused on their application for health and fitness purposes (Choi and Kim, 2016) or electronic textiles (Berzowska, 2005) with more focus on the technology itself than on the consumer perspective (Choi and Kim, 2016).

In recent years, different wearable technologies have been launched by luxury fashion brands, embracing both high-tech functionality and fashionable design (Wright and Keith, 2014; Hartmans, 2018). The Louis Vuitton Tambor Horizon smartwatch or the Tag Heuier Connected Modular watch are examples of smartwatches that have become luxury accessories rather than mere functional timekeepers (Hartmans, 2018). They may be appealing for the Millennial generation, described as the next prominent consumers of global luxury (Higgins et al., 2016) as well as the largest users' group of wearable technologies (Gartner, 2017). They are attracted by the innovativeness of smartwatches notwithstanding they are regarded as the first high-tech generation (Young and Hinesly, 2012).

In order to understand consumers' intentions to adopt new technologies, the TAM model (Davis, 1986) has been applied to study smartwatch adoption (Kim and Shin, 2015; Choi and

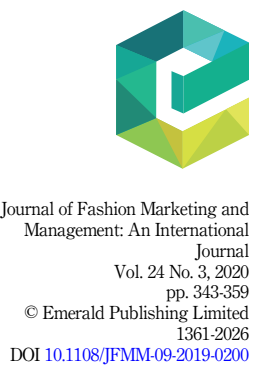


JFMM 24,3

\section{4}

Kim, 2016). However, previous studies considered functional (perceived usefulness and ease of use) and personal (need for uniqueness and vanity) variables, neglecting the influence of emotional and social factors. For the case of luxury smartwatches, the values that drive Millennial consumers' luxury consumption are conceived to play a critical role in affecting the adoption. Wiedmann et al. (2007) propose a model of luxury values, comprising individual, social and functional values, with results especially relevant to the study of this topic.

Evaluating smartwatch adoption from a consumer perspective makes it imperative to refer to the Theory of Reasoned Action (TRA) (Ajzen and Fishbein, 1975), which provides a fundamental framework for understanding consciously intended consumer behaviour (Yousafzai et al.,2010). Under TRA, the impact of consumer attitudes and subjective norms on actual behaviour are mediated by behavioural intentions which are formed based on personal and social factors. Behavioural intention has been considered as the most powerful predictor of human behaviour (Ajzen and Fishbein, 2005) and the association attitude-intentionbehaviour has been extensively validated in various contexts (i.e. Paul et al., 2016; Mishra et al., 2014; Yousafzai et al., 2010). Yet, little research has studied this attitude-intention link in luxury fashion smartwatch adoption which this study intends to address.

Consequently, this research aims to examine the relationship between key value propositions of luxury fashion smartwatches, consumer attitudes and their purchase intentions, and to explore Millennial consumers' overall perceptions of using these wearable technologies. This study proposes the following research questions:

$R Q 1$. What are the key factors influencing Millennial consumers perceptions and purchase intentions of luxury fashion?

$R Q 2$. How do functional, social and individual dimensions influence Millennial consumers' attitudes towards using luxury fashion smartwatches?

RQ3. What is the relationship between consumer attitudes towards using luxury fashion smartwatches and purchase intentions?

To achieve this, the paper is organised as follows: the next section reviews literature on wearable technology and luxury fashion smartwatches, consumer attitudes and purchase intention and technology acceptance model theories from which hypotheses ensue. The subsequent sections focus on the research methodology, then key results are presented and discussed. Finally, the last section expands on theoretical and managerial implications, concluding with limitations and directions for future research.

\section{Literature review}

Wearable technology and luxury fashion smartwatches

Wearable technologies are high-tech devices integrated into clothing, accessories or the human body to provide personalised functions to users, regardless of the types of usage (Choi and Kim, 2016). One of these high-tech devices are smartwatches which are worn like standard watches and allow the installation and use of mobile apps enabling connectivity and interactivity (Chuah et al., 2016). Smartwatches were the first commercialised wearable technology for consumers and the most popular one (Choi and Kim, 2016). Park et al. (2016) refer to smartwatches as multi-category products as they are perceived as an extension of a smartphone, which is also a watch (Choi and Kim, 2016). While luxury watches are associated with a high level of heritage value, lastingness, exclusivity and visibility (Chevalier and Mazzalovo, 2008), it could be stated that luxury smartwatches are an important and pioneering sub-category of broader smart-fashion.

The concept of luxury is dynamic and multifaceted (Berry, 1994; Wiedmann et al., 2007) and can be defined from functional, social and psychological perspectives. Luxury, often associated with well-known, highly credible and exclusive brands (Chevalier and Mazzalovo, 
2008), is consumed primarily for gaining social recognition, status or positive self-image in addition to their functional utilities (Kapferer, 1997; Vigneron and Johnson, 1999, 2004). Vigneron and Johnson (2004) developed luxury consumption motivations related to personal perceptions such as extended-self -integrating symbolic meanings into personal identity and hedonism - intrinsic and emotional benefits of luxury consumption, such as sensory pleasure stimulation (Kapferer, 1997, De Barnier and Valette-Florence, 2013). They also identified non-personal perceptions such as quality-characteristics of the product like design, sophistication and craftsmanship, conspicuousness-gaining social appraisal and achieving a more positive self-esteem, (Godey et al., 2013) and uniqueness - built on scarcity and exclusivity (Tian et al., 2001; Vigneron and Johnson, 2004). Thus, this conceptualisation highlights the social, hedonistic and functional purposes of luxury consumption, which was further extended by Wiedmann et al. (2007). This research recognises the importance of the personal and non-personal dimensions of luxury as key factors affecting luxury fashion smartwatch adoption and categorises them into functional, individual and social dimensions of using luxury fashion smartwatches (Wiedmann et al., 2007).

\section{Consumer attitudes and purchase intention}

Attitudes, as individual's learned predispositions (Fishbein and Ajzen, 1977), can be defined as the overall subjective evaluation of an entity, either positively or negatively (Ajzen and Fishbein, 2005). More specifically, an attitude is a construct of cognition, affect and conation (Fishbein and Ajzen, 1977), which depict the relationship between consumer attitudes and purchase behaviour as a process of learn, feel and do (Schiffman and Wisenblit, 2015).

According to Fishbein and Ajzen (1977), the cognitive component represents the understanding and perceptions of the features of an attitude entity. This knowledge and interpretation may be acquired directly through experience or indirectly through different information sources (Ajzen and Fishbein, 2005; Schiffman and Wisenblit, 2015). The affective component relates to the emotions and feelings that reveal satisfaction or dissatisfaction and can be either positive or negative (Schiffman and Wisenblit, 2015; Solomon et al., 2013). Last, the conation component is associated with the propensity to perform a behaviour (Fishbein and Ajzen, 1977) and is often expressed in terms of a consumer's intention to buy/use (Sethna and Blythe, 2016). This way, purchase intention is considered the closest cognitive predecessor to actual behaviour (Bagozzi et al., 1989). Consumers attitudes towards an object may not necessarily predict their behaviour (Hogg et al., 2006; Solomon et al., 2013) so the attitude towards a specific behaviour is considered more effective in predicting that behaviour (Fishbein and Ajzen, 1977; Liska, 1974; Schiffman and Wisenblit, 2015; Zhang et al., 2008). It captures consumers' attitude towards acting or using an object (Schiffman and Wisenblit, 2015) instead of merely the attitude towards the object itself (Park et al., 2016).

Purchase intention is defined as the likelihood that an individual performs in a specific way towards the usage and acquirement of an object (Fishbein and Ajzen, 1977). In the context of technology adoption, purchase intentions refer to adoption intention (Davis , 1989; Venkatesh and Davis, 2000) and willingness to use a new technology (Choi and Kim, 2016). Previous research suggests that the attitude towards smartwatches positively influences the intention to use the smartwatch (Choi and Kim, 2016; Chuah et al., 2016). Yet, little is known about consumer attitudes towards using luxury fashion smartwatches, which are considered central to the adoption intention and are of particular importance for practitioners.

In luxury consumption, consumers' perceptions of social, individual and functional values of luxury can be related to their purchase intentions (Hung et al., 2011). Regarding Millennial's luxury consumption, social status (Eastman et al., 2013) and self-esteem (Giovannini et al., 2015) are expected to generate favourable attitudes towards luxury consumption and strengthen the luxury brand purchase intentions. 
JFMM

24,3

346

\section{Technology acceptance models}

The Theory of Reasoned Action (TRA) (Ajzen and Fishbein, 1975) provides a framework for understanding consciously intended consumer behaviour (Yousafzai et al., 2010). It posits that the impact of consumer attitudes and subjective norms on actual behaviour are mediated by behavioural intentions, which is considered the most powerful predictor of human behaviour (Ajzen and Fishbein, 2005).

In order to predict consumers' intentions to adopt emerging technologies the Technology Acceptance Model (TAM) (Davis, 1986) has been widely applied. It depicts that perceived usefulness and perceived ease of use are two critical variables influencing users' beliefs, attitudes and intentions to embrace a new information system (Legris et al., 2003). An extension of TAM, TAM 2 (Venkatesh and Davis, 2000) denotes the influence of subjective norm on behavioural intentions. Consequently, technology adoption is regarded as a process of social influence. TAM has been extensively applied to explain consumer acceptance of e-commerce (Pavlou, 2003), mobile payment (Schierz et al., 2010), smart glasses (Raushnabel and Ro, 2016), mobile learning systems (Park et al., 2012) and standard smartwatches launched by IT brands (Kim and Shin, 2015; Choi and Kim, 2016). Yet, despite considerable research on the application of TAM, studies incorporating TAM 2 to explain consumers' perceptions, attitudes and intentions towards using luxury fashion wearables is still scarce.

Luxury fashion wearable technology products embrace both high-tech functionality and fashionable design. These smartwatches are marketed as luxurious accessories, rather than solely functional digital devices, as self-expressive use of them has become more commonplace. Furthermore, Millennial consumers generally consume luxury for socialoriented purposes (Eastman and Liu, 2012). Hence, values that drive Millennial consumers' luxury consumption, along with factors proposed in TAM 2, are perceived to play a critical role in affecting the adoption of these smart accessories.

While Choi and Kim (2016) provided a first step towards understanding consumers' perceptions of smartwatches, the authors did not consider emotional and social factors. Within the context of consumer behaviour watches are consumed primarily for aesthetic appeal, as well as providing a means for constructing self-identity. Thus, psychological and social motivations may also be considered as antecedents to luxury fashion smartwatch adoption.

\section{Theoretical framework and hypotheses development}

This research builds on TAM 2, TRA and Luxury Perception models to examine the relationships between key value propositions of luxury fashion smartwatches, Millennial consumers' attitudes and purchase intentions, and to explore their overall perceptions towards using the luxury fashion smartwatches. Based on these theories, a theoretical framework (see Figure 1) has been developed from which nine hypotheses have been formulated.

The model posits that Millennial consumers develop attitudes and purchase intentions towards luxury fashion smartwatches in three stages. In line with the tri-component attitude model (Fishbein and Ajzen, 1977), consumers learn about luxury fashion smartwatches at the first phase (cognition). The second phase (affective) involves the formation of consumers' attitudes towards using luxury fashion smartwatches. At the final phase (conation), consumers develop intentions to buy consistent with their overall evaluations. Drawing on the TRA, a relationship between consumer attitudes and purchase behaviour in terms of learning, feeling and doing (Solomon et al., 2013) is depicted.

\section{Functional dimension of using luxury fashion smartwatches}

The effect of functional performance on consumers' attitudes and adoption intentions has been studied extensively and is generally accepted that functional factors are the core reasons 


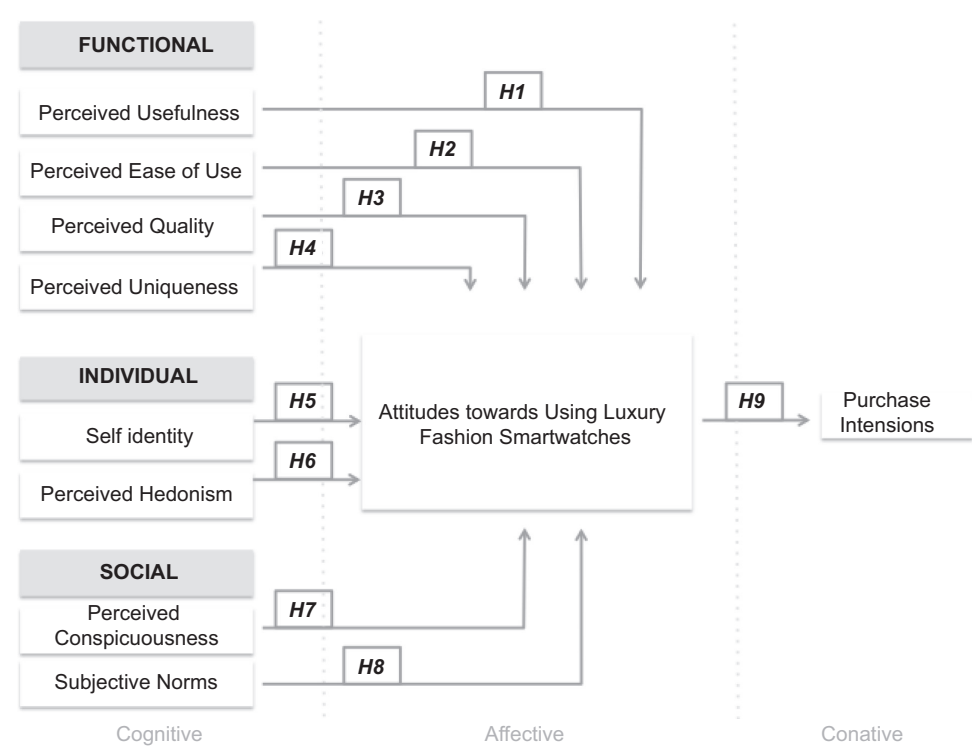

Source(s): Author's own

Millenials perceptions wearables

for smartwatch adoption (Raushnabel and Ro, 2016). In addition, luxury consumption research also suggests that consumers' propensity to consume luxury may be explained by functional motives (Berthon et al., 2009). In this study, the functional dimension addresses product-related attributes, including perceived usefulness, perceived ease of use, perceived quality, and perceived uniqueness.

Perceived usefulness. As specified in TAM 2, the concept of perceived usefulness implies the degree to which users believe adopting such innovation will improve their job enactment (Venkatesh and Davis, 2000). It is found to have an impact on consumer attitudes towards using that technology. For example, Choi and Kim (2016) reported a positive and significant relationship between perceived usefulness and consumer attitudes towards using smartwatches. This view is generally supported in the field of wearable adoption research (Chuah et al., 2016; Kim and Shin, 2015). Yet, whether the results are transferrable to luxury fashion smartwatches is unknown. Therefore, $\mathrm{H1}$ is proposed

H1. Perceived usefulness is significantly related to the positive attitudes towards using luxury fashion smartwatches.

Perceived ease of use. Perceived ease of use is another utilitarian factor involved in TAM 2, which can be understood as the extent to which a user believes adopting an innovation will be uncomplicated (Venkatesh and Davis, 2000). Regarding the relationship between perceived ease of use and attitudes towards using smartwatches, previous research findings are contradictory and inconclusive. While Kim and Shin (2015) demonstrated a positive relationship between perceived ease of use and attitudes towards using smartwatches, Chuah et al. (2016) suggested that there is no direct relationship between both constructs. This study examines the relationship between perceived ease of use and consumers' attitudes towards using luxury fashion smartwatches.

H2. Perceived ease of use is significantly related to the positive attitudes towards using luxury fashion smartwatches. 
JFMM 24,3

\section{8}

Perceived quality. Within the context of luxury consumption, premium quality is perceived as fundamental (Wiedmann et al., 2009) and previous studies have demonstrated how consumers' perceptions of quality have a significant influence on luxury consumption (Bian and Forsythe, 2012; De Barnier et al., 2006). Likewise, young consumers generally connect luxury goods to excellent quality and reassurance (Godey et al., 2013). Ressel (2016) also reported that Millennial consumers' possession of luxury increases when they associate luxury with quality.

H3. Perceived quality is significantly related to the positive attitudes towards using luxury fashion smartwatches.

Perceived uniqueness. The concept of perceived uniqueness is based on the perception of exclusivity and rarity (Vigneron and Johnson, 2004). Several studies have revealed that perceived uniqueness could enhance consumers' aspiration of possessing luxury items (Bian and Forsythe, 2012) as it helps them to differentiate from others (Wiedmann et al., 2007), and express their individuality (Hennigs et al., 2012). For Millennial consumers, they seek to show unique qualities (Eastman and Liu, 2012). In the field of smartwatch adoption, Choi and Kim (2016) suggested consumers' need for uniqueness might be conceived as a potentially important factor.

H4. Perceived uniqueness is significantly related to the positive attitudes towards using luxury fashion smartwatches.

\section{Individual dimension of using luxury fashion smartwatches}

In the context of luxury consumption, personal-oriented factors may affect consumer perceptions of luxury consumption (Vigneron and Johnson, 2004). These factors often relate to intrinsic desires and needs for luxury (Stegemann, 2006). This study addresses the individual dimension of luxury fashion smartwatch adoption in terms of self-identity and perceived hedonism.

Self-identity value. Self-identity relates to how a person perceives themselves (Klarmann et al., 2013). This dimension illustrates that consumers consume luxury to construct and express a favourable self-image (Hudders and Pandelaere, 2013), by incorporating the symbolic meaning of luxury into their individual self-identity (Vigneron and Johnson, 2004). These luxury products are preferred because the consumer perceives a congruity between themselves and product-image (Birdwell, 1968; Oyserman, 2009).

H5. Self-identity is significantly related to the positive attitudes towards using luxury fashion smartwatches.

Perceived hedonism. Perceived hedonism is considered as a subjective and intangible emotional benefit, which consumers may obtain through luxury consumption (Wiedmann et al., 2009). Recent studies show that perceived enjoyment resulted from smartwatch usage positively influences adoption intentions (Choi and Kim, 2016). Following this, it is expected that Millennial consumers' attitudes towards using luxury fashion smartwatches may be influenced by their hedonic responses.

H6. Perceived hedonism is significantly related to the positive attitudes towards using luxury fashion smartwatches.

\section{Social dimension of using luxury fashion smartwatches}

The social-oriented motives have long been considered as the core reasons for luxury consumption, i.e. status expression and social approval (Belk, 1985; Godney et al., 2013). In smartwatch adoption research, Choi and Kim (2016) and Chuah et al. (2016) provided 
important first steps in incorporating social factors into their research. In this study, perceived conspicuousness and subjective norms are recognised as the social factors that may affect Millennial's luxury fashion smartwatch purchase intentions.

Perceived conspicuousness. Conspicuousness refers to consumers' search for social status and recognition (Berger and Ward, 2010). This suggests consumers consume luxury primarily for displaying their wealth, prestige and social status (Stegemann, 2006), which ultimately enables them to construct a favourable social image and reinforce their status within their reference groups (Godey et al., 2013). As aforementioned, Millennial consumers are more prestige sensitive and inclined towards status consumption as they see luxury possession as an indication of success (Eastman and Eastman, 2015).

H7. Perceived conspicuousness is significantly related to the positive attitudes towards using luxury fashion smartwatches.

Subjective norm. Subjective norm is related to consumer's perception of pressure or expectation from the social group to perform certain behaviour (Ajzen and Fishbein, 2000; Kim et al., 2009).

It has been found that users' attitude towards using a technology is positively influenced by subjective norm (Rogers, 2010; Mishra et al., 2014). Previous research has arisen that Millennials are more vulnerable to peer pressure and they purchase luxury to conform to their reference groups (Grotts and Widner Johnson, 2013).

H8. Subjective norm is significantly related to the positive attitudes towards using luxury fashion smartwatches.

Attitudes towards using luxury fashion smartwatches and purchase intention

The theory of attitude-toward-behaviour has been captured in TAM 2 and TRA models. In the field of smartwatch adoption, scholars generally support that attitudes positively predict adoption intentions (Chuah et al., 2016; Choi and Kim, 2016; Kim and Shin, 2015). Hence, it can be hypothesised a positive relationship between attitudes towards using luxury fashion smartwatches and purchase intentions (see Table 1).

H9. Positive attitudes towards using luxury fashion smartwatches is significantly related to the purchase intentions.

\section{Methodology}

In order to provide a detailed understanding of factors influencing Millennial consumers' attitudes towards using luxury fashion smartwatches and purchase intentions, mixed methods were employed in this research (Creswell, 2014). The majority of existing studies on smartwatch adoption tend to use purely quantitative methods (i.e. Choi and Kim, 2016). Thus, it is believed that the use of mixed methods to study the smartwatch phenomenon may provide a more comprehensive understanding of the issue and reduce bias in data sources. A questionnaire followed by qualitative focus groups has been employed.

For the research sequence, a convergent parallel mixed methods approach was implemented. Quantitative and qualitative data were collected simultaneously; whereas analyses were conducted separately in a complementary manner (Creswell, 2014). In the final stage, quantitative and qualitative findings were integrated using triangulation and complementarity for comparison and interpretation to produce more complete and wellvalidated discussion (Golafshani, 2003). The questionnaire identified key factors affecting Millennial consumers' attitudes towards using luxury fashion smartwatches and their purchase intentions. Additionally, the two focus groups further explored their perceptions and explained why certain factors influenced their attitudes towards using luxury fashion smartwatches. Overall, the purpose of this complementary design was to explore the 


\section{JFMM 24,3}

H1 Perceived usefulness is significantly related to the positive attitudes towards using luxury fashion smartwatches

H2 Perceived ease of use is significantly related to the positive attitudes towards using luxury fashion smartwatches

H3 Perceived quality is significantly related to the positive attitudes towards using luxury fashion smartwatches

H4 Perceived uniqueness is significantly related to the positive attitudes towards using luxury fashion smartwatches

H5 Self-identity is significantly related to the positive attitudes towards using luxury fashion smartwatches

H6 Perceived hedonism is significantly related to the positive attitudes towards using luxury fashion smartwatches

H7 Perceived conspicuousness is significantly related to the positive attitudes towards using luxury fashion smartwatches

H8 Subjective norm is significantly related to the positive attitudes towards using luxury fashion smartwatches

Table 1.

Summary of research hypotheses
H9 Positive attitudes towards using luxury fashion smartwatches is significantly related to purchase intentions

Source(s): Author's own

consumers' attitudes and perceptions in greater details, by mutually enhancing the analysis and understanding of each dimension to produce more substantiated results (Wolff et al., 1993). This research is therefore explanatory in nature, where the causal relationship between variables is established, followed by qualitative data analysis to explain how and why consumers perceive things in a particular way.

The questionnaire was built on previous validated scales. First, as luxury fashion smartwatches are still in an early stage of development a clear definition of them was given and picture prompts were used to provide examples for respondents. In terms of measurement items and scale construction, consumers' attitudes towards using luxury fashion smartwatches from a functional dimension were adapted from Ventakesh and Davis (2000), Chuah et al. (2016), Kim and Shin (2015) and Wiedmann et al. (2009). Regarding the individual dimension, self-identity was derived from Wiedmann et al. (2009) and perceived hedonism from Arnolds and Reynolds (2003). For the social dimension, perceived conspicuousness scales were adapted from Giovannini et al. (2015) and subjective norm were derived from Sweeney and Soutar (2001). Last, attitudes measurement was based on Kim and Shin (2015) and Siegel et al. (2014), while purchase intention items were adapted from Bian and Forsythe (2012).

Focus groups are specifically helpful in exploring individuals' perceptions and answering the questions of what, how and why they think that way (Kitzinger, 1995). Therefore, focus groups in this study were used for a broader exploration of the research subjects, by extending and elaborating on consumers' perceptions and attitudes formation (Creswell, 2014). They aim to complement and offer further insight into the previous quantitative enquiry. In view of that, two semi-structured focus-group with a total 10 participants were conducted aiming to better understand Millennial consumer perceptions of using luxury fashion smartwatches (see Table 2). Purposeful random sampling was employed to identify Millennial participants that were a mix of smartwatch users and non-users. The questions were designed following Choi and Kim (2016) and Krueger and Casey's (2002) previous research.

Thematic analysis was used for analysing qualitative data in a process that involved identifying themes and sub-themes and establishing meanings through coding qualitatively (Myers, 2013). According to Miles and Huberman (1994), a theme is a thread of underlying meaning through condensed meaning units or codes that can be divided into relevant subthemes (Krippendorf, 2012). In this study, combinations of emerging (based on information collected from participants) and predetermined (based on proposed research framework) 
themes were identified. This strengthens the study validity as themes are identified based on converging sources (Creswell, 2014).

\section{Results}

Quantitative study

A total of 344 questionnaires were collected where 312 were regarded as valid responses. Descriptive statistics show that sample demographics included $61 \%$ of female respondents and $39 \%$ of males. Approximately $53 \%$ of them were aged $25-37$, while $47 \%$ of them belonged to the younger age group of 17-24. This is significant, as it is recognised that differently aged consumers may have dissimilar purchasing powers and their buying motivations may vary (Solomon et al., 2013).

Reliability and validity. Cronbach's alpha was used to measure internal consistency of the scales used in this research. Cronbach's alpha coefficients ranged from to 0.809 to 0.969 , indicating good and excellent internal consistency of scales as it can be observed in Table 3 (George and Mallery, 2013).

To assess the validity of the constructs, a principal component analysis was conducted on the 29 items with orthogonal rotation. KMO is $0.908(>0.6)$ and Bartlett's Test is significant as $p=0.000(<0.05)$, so the dataset is appropriate for factor analysis.

Multiple regression analysis and correlation analysis. To test $\mathrm{H} 1-\mathrm{H} 8$ multiple regression analysis followed by correlation analysis were used. Multiple regression analysis was applied to investigate the importance of each of the independent variables in functional, individual and social dimensions to the prediction of dependent variable. The dependent variable is consumer attitude while the independent variables include perceived usefulness, perceived ease of use, perceived quality, perceived uniqueness, self-identity, perceived hedonism, perceived conspicuousness and subjective norm. Furthermore, the overall fit of the model was tested. All the predictors have a significant $(\phi=0.000<0.001)$ and positive correlation with consumers attitudes (Positive $r$ values). Of all predictors, perceived uniqueness correlates best with consumers' positive attitudes $(r=0.75, p<0.001)$, so it is likely that this variable best predicts consumers' positive attitudes towards using luxury fashion smartwatches.

Correlation analysis was conducted to explore the significance of relationships among variables. Results show a significant, strong and positive correlation between consumers' attitudes towards using luxury fashion smartwatches and perceived usefulness $(r=0.74)$, perceived hedonism $(r=0.70)$ and perceived uniqueness $(r=0.75)$, all $p=0.01(<\alpha=0.05)$. Perceived ease of use $(r=0.57)$, perceived quality $(r=0.69)$, self-identity $(r=0.43)$, perceived conspicuousness $(r=0.55)$ and subjective norm $(r=0.66)$ are significantly, positively and moderately correlated to consumers' positive attitudes towards using luxury fashion smartwatches, all $p=0.01(<\alpha=0.05)$.

\begin{tabular}{|c|c|c|c|c|c|}
\hline Respondent \# & Age & Gender & Occupation & Wearable user & \\
\hline 1 & $25-37$ & Male & Magazine editor & Apple smartwatch & \\
\hline 2 & $17-24$ & Female & Student & Michael Kors access smartwatch & \\
\hline 3 & $25-37$ & Female & Brand manager & LG \& Xiaomi smartwatch & \\
\hline 4 & $17-24$ & Male & Student & Samsung gear smartwatch & \\
\hline 5 & $25-37$ & Female & Fashion buyer & Apple smartwatch & \\
\hline 6 & $17-24$ & Male & Student & Xiaomi smartwatch & \\
\hline 7 & $25-37$ & Female & Student & N/A & \\
\hline 8 & $17-24$ & Female & Student & N/A & Table 2. \\
\hline 9 & $25-37$ & Male & Student & N/A & Focus group \\
\hline 10 & $25-37$ & Female & Merchandiser & N/A & participant profile \\
\hline
\end{tabular}

\section{Millenials perceptions wearables}

351




\begin{tabular}{|c|c|c|c|c|c|c|}
\hline \multirow[t]{4}{*}{$\begin{array}{l}\text { JFMM } \\
24,3\end{array}$} & \multicolumn{2}{|l|}{ Dimensions } & \multicolumn{2}{|c|}{$\begin{array}{c}\text { Cronbach's } \\
\text { alpha }\end{array}$} & \multirow{2}{*}{$\begin{array}{c}\begin{array}{c}N \text { of } \\
\text { items }\end{array} \\
4\end{array}$} & \multirow{2}{*}{$\begin{array}{l}\begin{array}{l}\text { Internal } \\
\text { consistency }\end{array} \\
\text { Excellent }\end{array}$} \\
\hline & Functional dimension & Perceived usefulness & 0.914 & 0.949 & & \\
\hline & & Perceived ease of use & 0.855 & & 4 & Good \\
\hline & & Perceived quality & 0.881 & & 3 & Good \\
\hline \multirow{5}{*}{352} & & Perceived uniqueness & 0.946 & & 4 & Excellent \\
\hline & Individual dimension & Self-identity & 0.809 & 0.911 & 4 & Good \\
\hline & & Perceived hedonism & 0.896 & & 3 & Good \\
\hline & Social dimension & $\begin{array}{l}\text { Perceived } \\
\text { conspicuousness }\end{array}$ & 0.935 & 0.949 & 3 & Excellent \\
\hline & & Subjective norm & 0.922 & & 3 & Excellent \\
\hline \multirow{3}{*}{$\begin{array}{l}\text { Table } 3 \text {. } \\
\text { Cronbach's Alpha } \\
\text { coefficients }\end{array}$} & Affective and behavioural & Attitudes & 0.916 & & 4 & Excellent \\
\hline & responses & Purchase intentions & 0.931 & & 3 & Excellent \\
\hline & Source(s): Author's own & & & & & \\
\hline
\end{tabular}

Overall, all the factors are found to have statistically significant influences on consumers' positive attitudes towards using luxury fashion smartwatches; thus, the hypotheses are supported. For the functional dimension of using luxury fashion smartwatches, perceived usefulness, perceived ease of use, perceived quality and perceives uniqueness have a significant influence on positive attitudes towards using them; for the individual dimension, self-identity and perceived hedonism have both a significant influence and for the social dimension, perceived conspicuousness and subjective norm also influence positive attitudes towards using luxury fashion smartwatches.

Bivariate correlation analysis. To test $\mathrm{H} 9$, bivariate correlation analysis was conducted to investigate the association between consumer attitudes towards using luxury fashion smartwatches and their purchase intentions. Results show $r(312)=0.749$ and $p=0.000$ $(<\alpha=0.05)$, and consequently, a strong, positive and statistically significant correlation between consumer attitudes towards using luxury fashion smartwatches and purchase intentions (at the 0.01 level). These results support H9 which means that positive attitudes towards using smartphone influence purchase intention.

\section{Qualitative results analysis and overall discussion}

As previously stated, a combination of emerging and predetermined themes were identified. Predetermined themes are based on the proposed research framework and include, for instance, the different dimensions of using luxury fashion smartwatches. Emerging themes come from the discussion such as recommendations and potential opportunities for smartwatches.

Each focus group started with a discussion about participants' perceptions of standard smartwatches and luxury fashion smartwatches. Most participants agreed that smartwatches were a positive technology mainly used for functional purposes, while for luxury fashion smartwatches practical utility was not a major determinant as they had similar functions as the standard one. The design and symbolic meanings were more relevant for them, as exemplified, "particularly I like their straps made by Hermes, which represents a lot about the craftsmanship and prestige of Hermes." (R1)

Perceptions of functional dimension of using luxury fashion smartwatches. Perceived quality was mentioned as the most relevant factor for using luxury fashion smartwatches and included aspects such as design and craftsmanship of these smartwatches, which is consistent with Vigneron and Johnson's (2004) findings. As R4 stated "luxury fashion smartwatches are supposed to have the highest quality and long lasting craftsmanship." (R4) Further, Godey et al. (2013) found that young consumers generally associate luxury goods to high quality. 
Participants also agreed that perceived uniqueness had a big impact on their adoption decision and in some cases, they associated this perceived uniqueness with enhanced social image, as expressed, "yea you know it's new and rare, not many people wearing it. So it does give you a lot of uniqueness and sophistication" (R10).

For participants it is imperative that luxury fashion smartwatches are still rare and limited in the market. Therefore, in line with Bian and Forsythe (2012), smartwatches help differentiate themselves from others and also enhances their individuality as fashion leaders and thus social affiliation. This enhanced desire for exclusivity further explains why personalisation and limited editions are highly valued by most participants, "I was surprised when I first saw the collaboration between Hermès and Apple. I think the price is reasonable because of such unique collaboration"(R5). Overall, consistent with Choi and Kim (2016), consumers' perception of uniqueness predicts their smartwatch adoption intentions.

Participants gave great emphasis to the compatibility between smartwatches and their smartphones to determine their usefulness. Additionally, the importance of perceived ease of use in adoption intentions was also highlighted. Some participants highlighted the practical value added to the luxury fashion smartwatch was a motivating factor to adopt it because its sophisticated design allowed them to use it for special occasions. "You can wear the fashion smartwatches to party; they have unique design, they are customised." (R2).

The quantitative results have demonstrated the significant impact of TAM factors (perceived usefulness and ease of use) on positive attitudes and intention towards using luxury fashion smartwatches, which is consistent with Kim and Shin's (2015) and Choi and Kim's (2016) research. In this study, focus group participants generally regarded usefulness as the core attribute of luxury fashion smartwatches. In addition, perceived ease of use is found to have greater importance than perceived usefulness. Similarly, Davis (1986) regarded perceived ease of use as a principle antecedent to perceived usefulness. Overall, the results demonstrate the application of TAM in explaining the adoption intention of luxury fashion smartwatches from the consumer perspective.

Perceptions of emotional dimension of using luxury fashion smartwatches. The results from the quantitative study show that intrinsic individual factors-perceived hedonism and selfidentity - impact on consumers' attitudes towards using luxury fashion smartwatches, which is also supported by previous literature (Giovannini, 2015). However, the qualitative insights show that this impact is limited in affecting participants' decision to use luxury smartwatches. While some participants described using them as emotionally satisfying, this tended to be associated with the positive social benefits offered such as social image construction, as evidenced, "my perception of purchasing a luxury fashion smartwatch is majorly hedonic. It gives a satisfaction being connected to such a prestigious luxury brand" (R3). It implies that factors motivating luxury fashion smartwatch adoption may be interrelated, as suggested by Rauschnabel and Ro (2016).

Several participants indicated that congruency between the brand and self-image was important as these smartwatches would represent them in some way, "I think how the brand suits my personality" (R2). Giovannini et al. (2015) also found that brand self-congruency significantly impacts Generation Y consumers' purchase intentions of luxury. Further, Sirgy (1985) also stated that consumers select particular brands to communicate their actual and ideal self-images.

Perceptions of social dimension of using luxury fashion smartwatches. There was general agreement that social motivations were very important in using luxury fashion smartwatches. Social status, a "luxury statement to others" (R6), was a key factor for many participants. Also, the importance of social recognition as a fashion leader and recommendations and approval from the social group were widely mentioned, "as a fashion buyer, I feel like wearing a trendy luxury fashion smartwatch can reinforce my image as a fashion leader." (R5) 
JFMM 24,3

According to participants, word-of-mouth has an important impact on participants' adoption decision. As does celebrity endorsement, as they are a source of symbolic meaning, "I saw Martha Hunt wearing a Michael Kors smartwatch. So she really influenced me to look into the Michael Kors Access line and I follow her a lot." (R2)

The social facet of motivation to use luxury fashion smartwatches is also linked to perceived conspicuousness. Perceived conspicuousness relates to positive attitudes towards using luxury fashion smartwatches and purchase intentions. Confirming Eastman et al.'s (2013) study, Millennial participants generally associated the use of luxury fashion smartwatches with personal ambition to show status, wealth or success. This is a contribution to existing research as luxury fashion smartwatches also embrace the luxury element, rather than simply representing a fashion accessory (Rauschnabel and Ro, 2016).

Another contribution of this study is extending findings of existing research in smartwatch adoption using TAM. It is demonstrated that subjective norm plays an important role in purchase intention formation, confirming the application of TAM 2. Focusgroups show a number of smartwatch users that purchased smartwatches under the influence of reference groups' word-of-mouth. For most of the respondents, using luxury fashion smartwatches is mainly motivated by their desires for social comparison, conformity to social groups, or gaining approval from aspirational groups. It is also confirmed by Grotts and Widner Johnson (2013) that Millennials consume luxury to gain a social standing in their reference groups. Similarly, Roger's (2010) asserted that peer pressure strongly affects innovation adoption. It is noteworthy that celebrities are conceived as a symbolic reference group by a number of participants. They associated themselves with the celebrity by using the luxury fashion smartwatches endorsed or used by that celebrity. This is because celebrities often represent an idealisation of an image or lifestyle that consumers admire (Kamins, 1990), and according to McCracken (1989), consumption of the endorsed products transfers the symbolic meaning of celebrities to the users.

Attitudes and purchase intentions. The relationship between consumer attitudes towards using luxury fashion smartwatches and purchase intention has been explored in this research. Both quantitative and qualitative data supports this relationship. Consistent with previous studies on smartphone adoption (i.e. Choi and Kim's, 2016, Chuah et al.'s, 2016 and Kim and Shin's, 2015), a positive and strong correlation between consumer attitudes towards using luxury fashion smartwatches and purchase intentions has been found.

Other factors affecting perceptions or adoption intention. Participants also reported a wide variety of other factors that might be influential in the adoption of luxury fashion smartwatches, including brand patronage, country-of-origin, or after-sale services. Marketing and communication, including good storytelling, would be a motivation to purchase luxury fashion smartwatches, "I think marketing would affect my purchase decision, like if they can tell a good story in which I am able to find myself associate with the brand. Then probably I would be more interested in it." (R4). Therefore, in terms of guiding marketing messages, storytelling should concentrate on communicating symbolic meanings and compelling stories that inspire and resonate with Millennial consumers (Sirgy, 1985).

Some participants tend to use country-of-origin as a means to evaluate the smartwatch quality and to guide their adoption. According to Godey et al. (2013), country-of-origin impacts consumer perceptions and behaviour through the interaction between brand image and country image. As such, participants consider that quality luxury fashion smartwatches should be made in Switzerland based on factors such as craftsmanship and history in watch making. "the reasons why I trust Rolex over all the others luxury fashion brands is because all their watches are made in Switzerland" (R7)

Another product/brand-related factor is brand loyalty. A number of participants expressed the degree to which they were connected to the brand would affect their purchase intention of luxury smartwatches. This may be related to the brand trust resulting 
from positive customer-brand relationship (Chaudhuri and Holbrook, 2001), which helps forge a strong consumer-brand connection (Keller, 2001).

\section{Implications, limitations and further research}

This study attempts to identify the key factors affecting Millennial consumers' attitudes and intentions towards using luxury fashion smartwatches, and to explore their overall perceptions of using these smartwatches. The focus is how do functional, individual and social dimensions influence consumers' attitudes and purchase intentions, building on established concepts in the field of technology adoption, luxury consumption and consumer behaviour.

In terms of theoretical implications, an important theoretical contribution of this study is to build on smartwatch adoption using TAM. It is proven that subjective norm plays an important role in purchase intention formation, confirming the application of TAM 2 . As the first empirical study on Millennial consumer behaviour towards luxury fashion smartwatch adoption, motivations behind their adoption intention are shown to link to functional, individual and social dimensions.

These findings provide practical implications for practitioners for growing wearable opportunities. Current marketing approaches that present merely conspicuousness and brand heritage may not be effective enough to elicit positive emotional responses from Millennial consumers. Results from this study demonstrate that effectively marketing luxury fashion smartwatches to this important generation requires communicating exclusivity and appealing brand story (Sirgy, 1985). Whilst the design, craftsmanship and compatibility of these smartwatches should also be emphasised.

This study provides an important first attempt to understand the Millennial consumers' perceptions of using luxury fashion smartwatches, but some limitations need to be acknowledged. This research is focused on the UK market and Millennial consumers. Future research could investigate if the relative importance of the factors identified varies in different cultures and across different age groups (Wiedmann et al., 2007). On the basis of empirical and theoretical contributions outlined, it is noted that perceived hedonism, usefulness, quality, conspicuousness and subjective norm are important factors in explaining consumers' adoption intentions of luxury fashion smartwatches. Other factors highlighted in the focus groups (e.g. brand loyalty, country-of-origin and after sales service) were not taken into consideration in this research framework and should be examined in the future. While the focus of this study remains on luxury fashion smartwatches, other types luxury fashion wearable such as bracelets, smart glasses and smart-clothing, warrant future research.

\section{References}

Ajzen, I. and Fishbein, M. (1975), Belief, Attitude, Intention and Behavior: An Introduction to Theory and Research, Addison-Wesley, MA.

Ajzen, I. and Fishbein, M. (2000), "Attitudes and the attitude-behavior relation: reasoned and automatic processes", European Review of Social Psychology, Vol. 11 No. 1, pp. 1-33.

Ajzen, I. and Fishbein, M. (2005), "The influence of attitudes on behavior", The Handbook of Attitudes, pp. 173-221.

Arnold, M.J. and Reynolds, K.E. (2003), "Hedonic shopping motivations", Journal of Retailing, Vol. 79 No. 2, pp. 77-95.

Bagozzi, R.P., Baumgartner, J. and Yi, Y. (1989), "An investigation into the role of intentions as mediators of the attitude-behavior relationship", Journal of Economic Psychology, Vol. 10 No. 1, pp. 35-62.

Belk, R.W. (1985), "Materialism: trait aspects of living in the material world", Journal of Consumer Research, Vol. 12 No. 3, pp. 265-280. 
JFMM

24,3

356

Berger, J. and Ward, M. (2010), "Subtle signal in inconspicuous consumption", Journal of Consumer Research, Vol. 37 No. 4, pp. 555-569.

Berry, C.J. (1994), The Idea of Luxury: A Conceptual and Historical Investigation, Cambridge University Press, Cambridge.

Berthon, P., Pitt, L., Parent, M. and Berthon, J.-P. (2009), “Aesthetics and ephemerality: observing and preserving the luxury brand”, California Management Review, Vol. 52 No. 1, pp. 45-66.

Berzowska, J. (2005), “Electronic textiles: wearable computers, reactive fashion, and soft computation”, Textile, Vol. 3 No. 1, pp. 58-75.

Bian, Q. and Forsythe, S. (2012), "Purchase intention for luxury brands: a cross cultural Comparison", Journal of Business Research, Vol. 65 No. 10, pp. 1443-1451.

Birdwell, A.E. (1968), "A study of the influence of image congruence on consumer choice", Journal of Business, Vol. 41 No. 1, pp. 76-88.

Chaudhuri, A. and Holbrook, M.B. (2001), "The chain of effects from brand trust and brand affect to brand performance: the role of brand loyalty", Journal of Marketing, Vol. 65 No. 2, pp. 81-93.

Chevalier, M. and Mazzalovo, G. (2008), Luxury Brand Management: A World of Privilege, John Wiley $\&$ Sons, New Jersey.

Choi, J. and Kim, S. (2016), "Is the smartwatch an IT product or a fashion product? A study on factors affecting the intention to use smartwatches", Computers in Human Behavior, Vol. 63, pp. 777-786.

Chuah, S.H.W., Rauschnabel, P.A., Krey, N., Nguyen, B., Ramayah, T. and Lade, S. (2016), "Wearable technologies: the role of usefulness and visibility in smartwatch Adoption", Computers in Human Behavior, Vol. 65, pp. 276-284.

Creswell, J.W. (2014), Research Design: Qualitative, Quantitative, and Mixed Methods Approaches, Sage Publications, Thousand Oaks, California.

Davis, F.D. (1986), "A technology acceptance model for empirically testing new end- user information systems: theory and results", Doctoral dissertation, MIT.

Davis, F.D. (1989), "Perceived usefulness, perceived ease of use, and user acceptance of information technology”, MIS Quarterly, Vol. 13 No. 3, pp. 319-340.

De Barnier, V. and Valette-Florence, P. (2013), "Culture and luxury: an analysis of luxury perceptions across frontiers", in Wiedmann, K.P. and Hennigs, N. (Eds), Luxury Marketing: A Challenge for Theory and Practice, Springer, New York, NY.

De Barnier, V., Rodina, I. and Valette-Florence, P. (2006), "Which luxury perceptionsaffect most consumer purchase behavior? A cross-cultural exploratory study in France, the United Kingdom and Russia”, Proceedings des Congrés Paris-Venise des Tendences Marketing, Paris, pp. 8-17.

Dehghani, M. and Kim, K.J. (2019), "The effects of design, size, and uniqueness of smartwatches: perspectives from current versus potential users", Behaviour and Information Technology, Vol. 38 No. 11, pp. 1143-1153.

Eastman, J.K. and Eastman, K.L. (2015), "Conceptualizing a model of status consumption theory: an exploration of the antecedents and consequences of the motivation to consume for status", Marketing Management Journal, Vol. 25 No. 1, pp. 1-15.

Eastman, J. and Liu, J. (2012), "The impact of generational cohorts on status consumption: an exploratory look at generational cohort and demographics on status Consumption", Journal of Consumer Marketing, Vol. 29 No. 2, pp. 93-102.

Eastman, J., Iyer, R. and Thomas, S. (2013), “The impact of status consumption on shopping styles: an exploratory look at the millennial generation”, Marketing Management Journal, Vol. 23 No. 1, pp. 57-73.

Fishbein, M. and Ajzen, I. (1977), Belief, Attitude, Intention, and Behavior: An Introduction to Theory and Research, Addison-Wesley, Reading, MA. 
Gartner (2017), "Millennials are at the forefront of the wearable world", available at: https://www. gartner.com/en/documents/3565917/millennials-are-at-the-forefront-of-the-wearable-world (accessed 16 December 2019).

George, D. and Mallery, P. (2013), IBM SPSS Statistics: 19 Step by Step a Simple Guide and Reference, 13th ed., Pearson, New York, NY.

Giovannini, S., Xu, Y. and Thomas, J. (2015), "Luxury fashion consumption and Generation Y consumers: self, brand consciousness, and consumption motivations", Journal of Fashion Marketing and Management, Vol. 19 No. 1, pp. 22-40.

Godey, B., Pederzoli, D., Aiello, G., Donvito, R., Wiedmann, K.P. and Hennigs, N. (2013), "An intercultural comparison of the perception of luxury by young consumers" in Wiedmann, K.P. and Hennigs, N. (Eds), Luxury Marketing: A Challenge for Theory and Practice, Springer, New York, NY.

Golafshani, N. (2003), "Understanding reliability and validity in qualitative research”, Qualitative Report, Vol. 8 No. 4, pp. 597-606.

Grotts, A. and Widner Johnson, T. (2013), "Millennial consumers' status consumption of handbags", Journal of Fashion Marketing and Management: International Journal, Vol. 17 No. 3, pp. 280-293.

Hartmans, A. (2018), "Nine of the most beautiful, expensive, smartwatches you can buy", available at: https://www.businessinsider.com/smartwatches-expensive-stylish-beautiful-2018-7? $\mathrm{r}=\mathrm{US} \& \mathrm{IR}=\mathrm{T}$ (accessed 16 December 2019).

Hennigs, N., Wiedmann, K.P., Klarmann, C., Strehlau, S., Godey, B., Pederzoli, D. and Taro, K. (2012), "What is the value of luxury? A cross-cultural consumer perspective", Psychology and Marketing, Vol. 29 No. 12, pp. 1018-1034.

Higgins, L., Higgins, L., Wolf, M.M. and Wolf, M.M. (2016), "Millennials as luxury wine buyers in the United States?", International Journal of Wine Business Research, Vol. 28 No. 3, pp. 190-205.

Hogg, M., Askegaard, S., Bamossy, G. and Solomon, M. (2006), Consumer Behaviour: A European Perspective, Prentice Hall, Upper Saddle River, New Jersey.

Hudders, L. and Pandelaere, M. (2013), "Indulging the self-positive consequences of luxury consumption", in Wiedmann, K.-P. and Hennigs, N. (Eds), Luxury Marketing: A Challenge for Theory and Practice, Springer, New York, NY.

Hung, K.P., Huiling Chen, A., Peng, N., Hackley, C., Amy Tiwsakul, R. and Chou, C.L. (2011), "Antecedents of luxury brand purchase intention", The Journal of Product and Brand Management, Vol. 20 No. 6, pp. 457-467.

Kamins, M.A. (1990), “An investigation into the "matchup” hypothesis in celebrity advertising: when beauty may be only skin deep", Journal of Advertising, Vol. 19, pp. 4-13.

Kapferer, J.N. (1997), "Managing luxury brands”, Journal of Brand Management, Vol. 4 No. 4, pp. 251-259.

Keller, K.L. (2001), "Building customer-based brand equity: a blueprint for creating strong brands", Marketing Science Institute, Report No. 01-107.

Kim, K.J. and Shin, D.H. (2015), “An acceptance model for smart watches: implications for the adoption of future wearable technology", Internet Research, Vol. 25 No. 4, pp. 527-541.

Kim, H.B., Kim, T.T. and Shin, S.W. (2009), "Modeling roles of subjective norms and eTrust in customers' acceptance of airline B2C eCommerce websites", Journal of Tourism Management, Vol. 30 No. 2, pp. 266-277.

Kitzinger, J. (1995), “Qualitative research. Introducing focus group”, British Medical Journal, Vol. 311 No. 7000, pp. 299-311.

Klarmann, C., Wiedmann, K.P. and Hennigs, N. (2013), "Luxury longing and counterfeit complicity: a consumer typology based on the perception of luxury value and counterfeit risk", in Wiedmann, K.-P. and Hennigs, N. (Eds), Luxury Marketing: A Challenge for Theory and Practice, Springer, New York, NY. 
JFMM

24,3

358
Krippendorff, K. (2012), Content Analysis: An Introduction to its Methodology, 4th ed., Sage, Thousand Oaks, CA.

Krueger, R.A. and Casey, M.A. (2002), "Designing and conducting focus group interviews", in Social Analysis, Selected Tools and Techniques, The World Bank, Washington, DC.

Legris, P., Ingham, J. and Collerette, P. (2003), "Why do people use information technology? A critical review of the technology acceptance model", Journal of Information and Management, Vol. 40 No. 3, pp. 191-204.

Liska, A.E. (1974), "Attitude-behavior consistency as a function of generality equivalence between attitude and behavior objects", Journal of Psychology, Vol. 86 No. 2, pp. 217-228.

McCracken, G. (1989), "Who is the celebrity endorser? Cultural foundations of the endorsement process", Journal of Consumer Research, Vol. 16 No. 3, pp. 310-321.

Miles, M.B. and Huberman, A.M. (1994), Qualitative Data Analysis: An Expanded Sourcebook, Sage, Thousand Oaks, CA.

Mishra, D., Akman, I. and Mishra, A. (2014), "Theory of reasoned action application for green information technology acceptance", Computers in Human Behavior, Vol. 36, pp. 29-40.

Myers, M.D. (2013), Qualitative Research in Business and Management, Sage, London.

Oyserman, D. (2009), "Identity-based motivation and consumer behavior", Journal of Consumer Psychology, Vol. 19 No. 3, pp. 276-279.

Park, S.Y., Nam, M.W. and Cha, S.B. (2012), "University students' behavioral intention to use mobile learning: evaluating the technology acceptance model”, British Journal of Educational Technology, Vol. 43 No. 4, pp. 592-605.

Park, Y.W., Son, S. and Kim, B. (2016), "Is smartwatch perceived as a wristwatch or a wearable device?: the experimental study for examining the categorization and the perceived fit with manufacturer on consumer evaluations", in Proceedings of the 18th Annual International Conference on Electronic Commerce: e-Commerce in Smart connected World, ACM.

Paul, J., Modi, A. and Patel, J. (2016), "Predicting green product consumption using theory of planned behavior and reasoned action”, Journal of Retailing and Consumer Services, Vol. 29, pp. 123-134.

Pavlou, P.A. (2003), "Consumer acceptance of electronic commerce: integrating trust and risk with the technology acceptance model", International Journal of Electronic Commerce, Vol. 7 No. 3, pp. 101-134.

Rauschnabel, P.A. and Ro, Y.K. (2016), "Augmented reality smart glasses: an investigation of technology acceptance drivers”, International Journal of Technology Marketing, Vol. 11 No. 2, pp. 123-148.

Ressel, C. (2016), "How millennial consumers have increased the demand for luxury brands", available at: https://core.ac.uk/download/pdf/80987390.pdf (accessed 16 December 2019).

Rogers, E.M. (2010), Diffusion of Innovations, The Free Press, New York, NY.

Schierz, P.G., Schilke, O. and Wirtz, B.W. (2010), "Understanding consumer acceptance of mobile payment services: an empirical analysis", Journal of Electronic Commerce Research and Applications, Vol. 9 No. 3, pp. 209-216.

Schiffman, L.G. and Wisenblit, J. (2015), Consumer Behavior, 11th ed., Pearson Education, England.

Sethna, Z. and Blythe, J. (2016), Consumer Behavior, 3rd ed., Sage, California.

Siegel, J.T., Navarro, M.A., Tan, C.N. and Hyde, M.K. (2014), "Attitude-behavior consistency, the principle of compatibility, and organ donation: a classic innovation”, Health Psychology, Vol. 33 No. 9, p. 1084.

Sirgy, M.J. (1985), "Using self-congruity and ideal congruity to predict purchase motivation”, Journal of Business Research, Vol. 13 No. 3, pp. 195-206. 
Solomon, M., Russell-Bennett, R. and Previte, J. (2013), Consumer Behavior: Having, Buying, Being, Pearson, Frenchs Forest, NSW.

Statista, (2019), "Wearable technologies. Statistics and facts", Statista, March 2019, available at: https://www.statista.com/topics/1556/wearable-technology/ (accessed 16 December 2019).

Stegemann, N. (2006), "Unique brand extension challenges for luxury brands", Journal of Business and Economics Research, Vol. 4 No. 10, pp. 57-68.

Sweeny, J.C. and Soutar, G.N. (2001), "Consumer perceived value: the development of a multiple item scale", Journal of Retailing, Vol. 77 No. 2, pp. 203-220.

Tian, K.T., Bearden, W.O. and Hunter, G.L. (2001), “Consumers' need for uniqueness: scale development and validation", Journal of Consumer Research, Vol. 28, pp. 50-66.

Venkatesh, V. and Davis, F.D. (2000), "A theoretical extension of the technology acceptance model: four longitudinal field studies", Management Science, Vol. 46 No. 2, pp. 186-204.

Vigneron, F. and Johnson, L.W. (1999), "A review and a conceptual framework of prestige-seeking consumer behavior", Academy of Marketing Science Review, Vol. 1999 No. 1, pp. 1-15.

Vigneron, F. and Johnson, L.W. (2004), "Measuring perceptions of brand luxury", Journal of Brand Management, Vol. 11 No. 6, pp. 484-506.

Wiedmann, K.P., Hennigs, N. and Siebels, A. (2007), "Measuring consumers' luxury value perception: a cross-cultural framework", Academy of Marketing Science Review, Vol. 2007 No. 7, pp. 333-361.

Wiedmann, K.P., Hennigs, N. and Siebels, A. (2009), "Value-based segmentation of luxury consumption behavior", Psychology and Marketing, Vol. 26 No. 7, pp. 625-651.

Wolff, B., Knodel, J. and Sittitrai, W. (1993), "Focus groups and surveys as complementary research methods", in Morgan, D.L. (Ed.), Successful Focus Groups: Advancing The State of the Art, Sage Focus Editions, Online Publication.

Wright, R. and Keith, L. (2014), "Wearable technology: if the tech fits, wear it", Journal of Electronic Resources in Medical Libraries, Vol. 11 No. 4, pp. 204-216.

Young, A.M. and Hinesly, M.D. (2012), "Identifying Millennials' key influencers from early childhood: insights into current consumer preferences", Journal of Consumer Marketing, Vol. 29 No. 2, pp. 146-155.

Yousafzai, S.Y., Foxall, G.R. and Pallister, J.G. (2010), "Explaining internet banking behavior: theory of reasoned action, theory of planned behavior, or technology acceptance model?", Journal of Applied Social Psychology, Vol. 40 No. 5, pp. 1172-1202.

Zhang, P., Aikman, S.N. and Sun, H. (2008), "Two types of attitudes in ICT acceptance and use", International Journal of Human-Computer Interaction, Vol. 24 No. 7, pp. 628-648.

\section{Further reading}

Bughin, J., Doogan, J. and Vetvik, O.J. (2010), “A new way to measure word-of-mouth marketing”, McKinsey Quarterly, Vol. 2, pp. 113-116.

Heugel, A. (2015), "Status consumption and the millennial consumer: an exploratory study", University Honors Program Theses, Vol. 83.

Fishbein, M. and Ajzen, I. (2011), Predicting and Changing Behavior: The Reasoned Action Approach, 1st ed., Taylor \& Francis, New York, NY.

\section{Corresponding author}

Marta Blazquez can be contacted at: marta.blazquezcano@manchester.ac.uk

For instructions on how to order reprints of this article, please visit our website:

www.emeraldgrouppublishing.com/licensing/reprints.htm

Or contact us for further details: permissions@emeraldinsight.com 